\title{
Locking Stand-Alone Cage Constructs for the Treatment of Cervical Spine Degenerative Disease
}

\author{
Roberto Alfonso De Leo-Vargas, Ildefonso Muñoz-Romero, \\ Michel Gustavo Mondragón-Soto, Jaime Jesús Martínez-Anda \\ Neurological Center, American British Cowdry Hospital, Mexico City, Mexico
}

\begin{abstract}
Study Design: Prospective case series study.
Purpose: Description of the outcome of stand-alone cervical cages for single and multilevel cervical degenerative spine disease. Overview of Literature: The aim of anterior cervical discectomy and fusion (ACDF) for cervical spine disease is to improve patient symptoms and spine stability and restore lordosis. Locking stand-alone cages were developed with the goal of minimizing soft tissue disruption anterior to the vertebrae and reducing the profile of the construct by avoiding an anterior plate, thereby maximizing ACDF benefits.

Methods: This study comprises a case series of patients surgically treated between July 2015 and February 2018 who received single or multilevel ACDF with a zero-profile stand-alone cervical cage. Surgical and clinical preoperative evaluation and surgical outcomes were evaluated using pre- and postoperative Nurick, Visual Analog Scale (VAS), Neck Disability Index (NDI), Japanese Orthopedic Association (JOA) score for myelopathy scales, cervical Cobb angles, postoperative surgical complications, and fusion and subsidence rates.

Results: Fifty-three patients underwent ACDF; the mean age of these patients was 58.8 years, and their preoperative VAS, NDI, and JOA scores were 8.1, 31.6, and 15.3, respectively. The preoperative Cobb angle was $30.7^{\circ}$. Forty-five percent of patients had onelevel, $54.7 \%$ had two-level, and $13.2 \%$ had three-level procedures. On preoperative magnetic resonance imaging, foraminal stenosis was present in $94.3 \%$ of patients, whereas medullar stenosis was present in $41.5 \%$. The rate of complications was $5.7 \%$ : two patients had postoperative dysphagia (3.7\%), and one patient had a surgical site hematoma. Mean postoperative follow-up time was 6.7 months; postoperative VAS, NDI, and JOA scores were 2.4, 15.9, and 15.8, respectively. Postoperative Cobb angle was $35.9^{\circ}$, fusion rate was $84.9 \%$, and subsidence rate was $11.3 \%$.

Conclusions: ACDF with zero-profile stand-alone cervical devices is an excellent option for cervical degenerative disc disease of one, two, and three levels, with similar results reported when using ACDF with either cage or plate.
\end{abstract}

Keywords: Cervical spondylosis; Spondylosis; Compressive myelopathy

\section{Introduction}

Cervical spondylosis disorders are common problems in clinical practice. If supportive medical treatment and physical therapy fail to relieve clinical symptoms, or if neurological deficits are present, surgery is indicated [1].

\footnotetext{
Received Sep 12, 2018; Revised Dec 4, 2018; Accepted Dec 7, 2018

Correspondence author: Jaime Jesús Martínez-Anda

Neurological Center, American British Cowdry Hospital, Av. Carlos Graef Fernández 154 int. 155, Col. Tlaxala Santa Fe., Delegación Cuajimalpa de Morelos C.P. 05300 Mexico City, Mexico

Tel: +52-5516617205, Fax: +52-16647199, E-mail: dr.martinezanda@gmail.com
} 
Anterior cervical discectomy and fusion (ACDF) is the treatment of choice for several cervical spinal diseases [2]; the goal of this procedure is to improve patient symptoms and spine stability and restore lordosis.

Anterior plate construct (APC), as described by Smith and Robinson [3], has been the 'gold standard' technique for ACDF. Several modifications to the original procedure have been developed, such as locking stand-alone cages (LSC), with the intent to reduce soft tissue disruption anterior to the vertebrae as well as to reduce postoperative dysphagia and the profile of the construct, thereby maximizing ACDF benefits [4].

The present study describes the clinical and radiographic outcomes with LSC for single and multilevel cervical degenerative disease.

\section{Materials and Methods}

This study comprises a prospective case series of surgically treated patients between July 2015 and February 2018 to resolve cervical spine degenerative disease; all patients were surgically treated by single or multilevel ACDF at the Neurological Center of American British Cowdry Hospital in Mexico City, Mexico, by a single surgeon (RdL) with a zero-profile $\mathrm{X}$-spine stand-alone cervical device. Investigation and ethical boards at American British Cowdry Hospital approved the study, and written informed consensts were obtained before surgery.

\section{Patients}

Inclusion criteria were: (1) signs and symptoms of cervical radiculopathy or spondylotic myelopathy, (2) cervical spondylosis confirmed using magnetic resonance imaging (MRI), and (3) follow-up of $\geq 3$ months. Exclusion criteria were: (1) ossification of the posterior longitudinal ligament, (2) developmental stenosis, (3) invasive malignancy, (4) evidence of systemic or local infection, and (5) history of previous cervical spine surgery.

\section{Clinical evaluation and outcome scores}

Clinical preoperative evaluation and surgical outcomes were evaluated using pre- and postoperative Nurick and Visual Analog Scale (VAS) for neck and radicular pain as well as Neck Disability Index (NDI) and Japanese Orthopedic Association (JOA) score for myelopathy. Data were prospectively collected during the preoperative evaluation and also immediately collected after surgery as well as 3 months, 6 months, and 12 months after surgery.

\section{Surgical technique}

Patients were placed in the supine position with neck hyperextension; the surgical site was exposed via a standard anterior approach and microscopic anterior cervical discectomy was performed. After dural decompression, interbody fusion was performed using a zero-profile Irix$\mathrm{C}$ cervical cage (X-spine Systems Inc., Miamisburg, $\mathrm{OH}$, USA). The cages were filled with demineralized bone matrix for fusion.

\section{Radiological evaluation}

Anteroposterior, lateral, and flexion-extension cervical radiographs were obtained before and immediately after surgery, as well as at 3 and 12 months after surgery (Fig. 1). MRI evaluation was preoperatively performed in all patients. Signs of medullar and radicular compression, Modic changes, disc degeneration (classification adapted from Pfirrmann lumbar classification [5]), and myelopathy signs were analyzed.

Cervical Cobb angles were measured pre- and postoperatively as the angle formed between a line parallel to the inferior endplate of C2 and a line drawn parallel to the inferior endplate of C7 [6]. Postoperative radiographs were analyzed for fusion and subsidence. Fusion was defined as (1) movement $<2^{\circ}$ in postoperative flexion-extension radiographs, (2) presence of trabeculae bridging bone formation at the anterior and/or posterior cortex of the
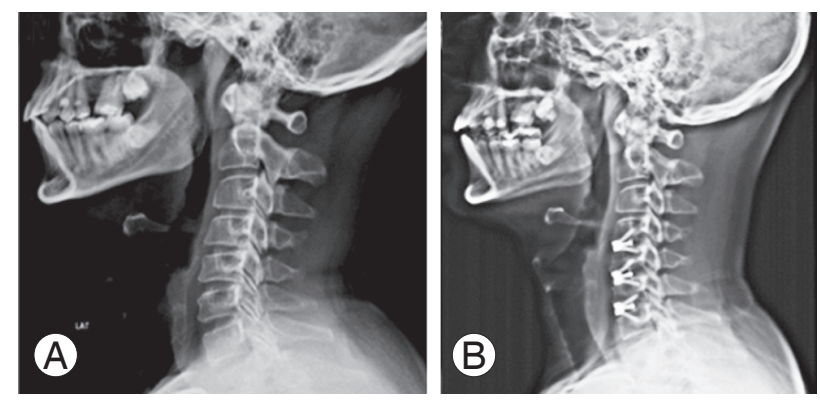

Fig. 1. Preoperative and postoperative plain radiographs of cervical spine in patients with locking stand-alone cage treatment. (A) Preoperative $\mathrm{X}$-ray displayed degeneration and abnormal physiologic curvature of the cervical spine. (B) Postoperative X-ray displayed good internal fixation and improvement of physiological curvature. 


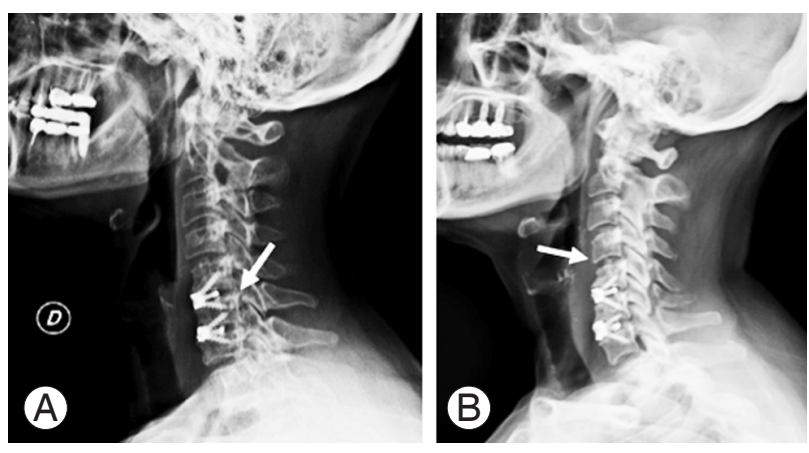

Fig. 2. (A) Presence of trabeculae bridging bone formation at the posterior cortex between surgically treated segments (arrow). (B) Adjacent segment changes above surgically treated segments (arrow).

involved vertebral bodies (Fig. 2B); and (3) absence of radiolucency through the fusion levels. Subsidence was defined as $\geq 3 \mathrm{~mm}$ reduction in the segmental height in postoperative images [1].

\section{Statistical analysis}

Descriptive statistics were used to describe epidemiological and clinical data. Fisher's $\chi^{2}$, Kruskall-Wallis and Student $t$-tests were used for univariate analysis. Statistical analyses were performed using IBM SPSS Statistics ver. 19.0 (IBM Corp., Armonk, NY, USA).

\section{Results}

\section{Patients}

Our analysis included a total of 53 patients who met the inclusion criteria for this study. The average age of the patients was 58.8 years; they had cervical or radicular symptoms for a period of approximately 14.8 months, and a follow-up time of 6.7 months. Thirty-four patients (64\%) were female, with a female to male ratio of 1.78:1 (Table 1).

In preoperative clinical evaluation, $32.1 \%$ of patients reported cervical pain, $11.3 \%$ reported radicular pain, and $56.6 \%$ reported both; mean preoperative VAS pain score was 8.1, with a mean NDI score of 31.6 (81.1\% of patients had at least moderate disability). Myelopathic symptoms were present in $56.6 \%$ of patients; $41.5 \%$ of patients had Nurick 1 myelopathy and a mean JOA score of 15.3 (Table 2).

Multilevel disc degeneration was present in $54.7 \%$ of patients; seven patients (13.2\%) had three-level disease. Forty-two patients (79.2\%) had C5-6 fusion as part of
Table 1. Clinical and epidemiological data

\begin{tabular}{|c|c|}
\hline Characteristic & Value \\
\hline No. of patients & 53 \\
\hline Age (yr) & 58.8 \\
\hline \multicolumn{2}{|l|}{ Gender } \\
\hline Female & $34(64.2)$ \\
\hline Male & $19(35.8)$ \\
\hline Time with symptoms (mo) & $14.8 \pm 16$ \\
\hline \multicolumn{2}{|l|}{ Levels $^{\mathrm{a})}$} \\
\hline Single level & $24(45.3)$ \\
\hline Two levels & $22(41.5)$ \\
\hline Three levels & $7(13.2)$ \\
\hline \multicolumn{2}{|l|}{ Type of pain } \\
\hline Cervical & $17(32.1)$ \\
\hline Radicular & $6(11.3)$ \\
\hline Both & $30(50.6)$ \\
\hline \multicolumn{2}{|l|}{ Nurick score } \\
\hline 0 & $23(43.4)$ \\
\hline 1 & $22(41.5)$ \\
\hline 2 & $7(13.2)$ \\
\hline 3 & $1(1.9)$ \\
\hline \multicolumn{2}{|l|}{ Radiological findings } \\
\hline \multicolumn{2}{|l|}{ Pfirrmann } \\
\hline 1 & 0 \\
\hline 2 & $2(3.8)$ \\
\hline 3 & $25(47.2)$ \\
\hline 4 & $24(45.3)$ \\
\hline 5 & $2(3.8)$ \\
\hline Listhesis & $8(15.1)$ \\
\hline Foraminal stenosis & $50(94.3)$ \\
\hline Central stenosis & $24(41.5)$ \\
\hline Myelopathy & $13(24.5)$ \\
\hline Cobbs angle $\left(^{\circ}\right)$ & $30.7 \pm 14.2$ \\
\hline Cervical myelopathy & $13(24.5)$ \\
\hline \multicolumn{2}{|l|}{ Modic changes } \\
\hline 0 & $35(66.0)$ \\
\hline 1 & $15(28.3)$ \\
\hline 2 & $3(5.7)$ \\
\hline
\end{tabular}

Values are presented as number, number (\%), or mean \pm standard deviation.

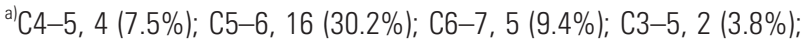
C4-6, 8 (15.1\%); C5-7, 11 (20.8\%); C4-7, 7 (13.2\%).

single or multilevel disease. All patients had at least Pfirrmann grade 2 disc degeneration; $96.2 \%$ of patients had 
Table 2. Clinical and surgical outcome

\begin{tabular}{|c|c|c|}
\hline Variable & $\begin{array}{c}\text { Mean } \pm \text { standard } \\
\text { deviation }\end{array}$ & $p$-value \\
\hline \multicolumn{3}{|l|}{ NDI (\%) } \\
\hline Preop & $31.6 \pm 11.6$ & $<0.001$ \\
\hline Postop & $15.9 \pm 8.5$ & \\
\hline Single level & $13.9 \pm 5.7$ & 0.88 \\
\hline Multilevel & $17.6 \pm 10.1$ & \\
\hline \multicolumn{3}{|l|}{ VAS score } \\
\hline Preop & $8.1 \pm 1.4$ & $<0.001$ \\
\hline Postop & $2.4 \pm 0.8$ & \\
\hline Single level & $2.2 \pm 0.8$ & 0.3 \\
\hline Multilevel & $2.5 \pm 0.7$ & \\
\hline \multicolumn{3}{|l|}{ JOA score } \\
\hline Preop & $15.3 \pm 1.8$ & $<0.001$ \\
\hline Postop & $15.9 \pm 1.2$ & \\
\hline Single level & $16.3 \pm 0.8$ & 0.016 \\
\hline Multilevel & $15.6 \pm 1.3$ & \\
\hline \multicolumn{3}{|l|}{ Cobb angle $\left({ }^{\circ}\right)$} \\
\hline Preop & $30.7 \pm 14.2$ & $<0.001$ \\
\hline Postop & $35.9 \pm 15.6$ & \\
\hline Single level & $29.8 \pm 15.6$ & 0.64 \\
\hline Multilevel & $31.4 \pm 13.2$ & \\
\hline Cobb angle change $\left({ }^{\circ}\right)$ & $5.77 \pm 6.5$ & \\
\hline Single level & $5.2 \pm 4.5$ & 0.56 \\
\hline Multilevel & $6.1 \pm 7.8$ & \\
\hline Fusion rate $(\%)$ & 84.5 & \\
\hline Single level & 95.8 & 0.04 \\
\hline Multilevel & 75.9 & \\
\hline NDI fusion & $16.3 \pm 8.9$ & 0.45 \\
\hline NDI no fusion & $13.5 \pm 6$ & \\
\hline VAS fusion & $2.4 \pm 0.8$ & 0.74 \\
\hline VAS no fusion & $2.3 \pm 0.9$ & \\
\hline Subsidence rate (\%) & 11.3 & \\
\hline Single level & 8.3 & 0.53 \\
\hline Multilevel & 13.8 & \\
\hline NDI subsidence & $14 \pm 7$ & 0.5 \\
\hline NDI no subsidence & $16.1 \pm 8.7$ & \\
\hline VAS subsidence & $2.3 \pm 0.5$ & 0.21 \\
\hline VAS no subsidence & $2.4 \pm 0.8$ & \\
\hline Surgical complications rate (\%) & 5.7 & \\
\hline Single level & 8.3 & 0.44 \\
\hline Multilevel & 3.4 & \\
\hline
\end{tabular}

(Continued to the next page)
Table 2. Continued

\begin{tabular}{llc} 
Variable & $\begin{array}{c}\text { Mean } \pm \text { standard } \\
\text { deviation }\end{array}$ & $p$-value \\
\hline AS changes (\%) & 17 & \\
\hline Single level & 12.5 & 0.4 \\
\hline Multilevel & 26 & \\
\hline NDI AS & $14.8 \pm 10$ & 0.5 \\
\hline NDI no AS & $16.1 \pm 8.3$ & \\
\hline VAS AS & $2.3 \pm 0.8$ & 0.9 \\
\hline VAS no AS & $2.4 \pm 0.8$ & \\
\hline
\end{tabular}

NDI, Neck Disability Index; Preop, preoperative; Postop, postoperative; VAS, Visual Analog Scale; JOA, Japanese Orthopedics Association; AS, adjacent segment.

disc degeneration of $\geq$ Pfirrmann 3. Eight patients (15.1\%) had listhesis, $94.3 \%$ had at least partial foraminal stenosis, and $44 \%$ showed Modic changes in at least one cervical level (Table 1).

Twenty-four patients (41.5\%) had at least partial central cervical stenosis; only $24.5 \%$ had signs of medullar myelopathy on MRI. On lateral X-ray, the mean preoperative Cobb angle was $30.7^{\circ} ; 79.2 \%$ of patients had lordotic preoperative cervical curvature (Table 1).

\section{Clinical outcome}

Three patients (5.7\%) developed postoperative complications. Two of these three patients (3.7\%) developed transient dysphagia, while the other patient had retropharyngeal hematoma, which was observed in postoperative $\mathrm{X}$-ray and did not compromise the airway; therefore, no further treatment was required. No significant differences were found between single or multilevel disease (Table 2).

On follow-up, all patients reported at least partial improvement in functional status and pain scale; VAS score improved from 8.1 to 2.4, NDI score improved from 31.6 to 15.9 , and JOA scale improved from 15.3 to 15.8 . All scales exhibited statistically significant improvement $(p \leq 0.001)$. No significant difference was found between single versus multilevel disease in clinical outcome (VAS or NDI); however, patients with multilevel disease had better improvement in postoperative JOA $(p=0.016)$ (Table 2$)$.

\section{Radiological outcome}

Fusion was documented in $84.9 \%$ of patients (Fig. 2A); 
$95.8 \%$ of patients with single level disease achieved postoperative fusion versus $75.9 \%$ of patients with multilevel disease. There was a significant difference between the single and multilevel disease groups $(p=0.04)$, but no difference between two- or three-level disease groups with regard to fusion indices. No significant difference was found between fusion and no-fusion groups in NDI score ( 16.3 versus $13.5, p=0.45$ ) or VAS scale ( 2.4 versus 2.3 , $p=0.74$ ) (Table 2).

Cage subsidence was found in six patients (11.3\%) with no significant difference between single or multilevel procedures. The cervical level that had higher indices of pseudoarthrosis and subsidence was C5-6 (88.8\% of fusion and $13.8 \%$ of subsidence). No significant difference was found between subsidence and no-subsidence groups in NDI score (14.7 versus $16.1, p=0.5)$ or VAS scale $(2.3$ versus $2.4, p=0.21$ ) (Table 2 ).

There was a mean $5.7^{\circ}$ change in cervical spine curvature, including a postoperative improvement in Cobb angle from $30.7^{\circ}$ to $35.9^{\circ}$, which was a significant difference $(p \leq 0.001)$ (Fig. 1); No significant difference was found between single or multilevel disease in cervical angle improvement $\left(5.2^{\circ}\right.$ versus $\left.6.1^{\circ}, p=0.56\right)$ (Table 2$)$.

We observed that nine patients (17\%) had adjacent segment changes in follow-up studies, but none had symptomatology attributable to the findings identified using imaging (Fig. 2B). No significant differences were found in adjacent segment changes between patients with single level or multilevel procedures. At follow-up, there was no significant difference in clinical outcome between patients with adjacent segment changes and patients with any findings in sequential image studies (Table 2).

\section{Discussion}

APCs for ACDF are effective in achieving immediate stability, improving cervical sagittal alignment, and increasing fusion rates, with a low profile of current anterior plating systems. More recently, there has been an increase in the use of the LSC, which does not require an anterior plate and minimizes cervical soft tissue disruption, thereby reducing the profile of the construct [4]. Studies have demonstrated the safety and efficacy of three-level ACDF with cages and plate fixation; however, complications associated with plate fixation (e.g., breakage, loosening of screws, screw penetration to endplate, triangle fracture, and visceral and vascular structural injuries) have been reported with multilevel ACDF [7]. Stand-alone cages appear to overcome these limitations of anterior plating, but there is disagreement regarding the use of stand-alone cages with respect to subsidence, cage migration, loss of cervical lordosis and fused segment angle, and relatively low fusion rate [8]. Some studies have indicated that zeroprofile LSC has a better clinical effect on cervical spondylosis, with fewer invasive surgical treatments than APC [9]. The surgical procedure for LSC is very simple and relatively short; it primarily requires tightening of screws after placement [10]. The operative time is significantly greater and blood loss is significantly higher with APC, compared with LSC, in single and multilevel procedures [11-13]. Surgical exposure and steps for plate insertion are time-consuming and increase soft tissue dissection, blood loss, and surgical time. We achieved excellent results with LSC for single and multilevel disease (Fig. 1), with significant improvement in NDI, JOA, and VAS scores. Clinical results in pain and functional scales between groups were similar in this case series; notably, a better outcome with regard to JOA score was observed in multilevel disease, given that that group had a higher incidence of central canal compromise. Few previous reports have addressed the comparison between single and multilevel cervical disease in the same case series. In this study, we found that clini$\mathrm{cal}$ and radiological outcomes were comparable between the groups.

APC might pose a substantial risk of hardware-related complications, such as plate dislodgement, soft tissue injury, tracheoesophageal lesions, and dysphagia $[14,15]$. Dysphagia is recognized as the earliest complaint after ACDF using an additional anterior plate. The reported incidence of transient dysphagia after ACDF ranges from $2 \%-71 \%$, and that of chronic dysphagia ranges from $3 \%-21 \%[14,16-18]$. Studies have found that LSC has a lower risk of dysphagia as a complication, compared with APC, in postoperative and follow-up periods [4]. Li et al. [18] reported a $6.8 \%$ incidence of postoperative dysphagia, as well as $2.8 \%$ incidence at 3 months postoperatively. We observed a $3.7 \%$ incidence of transient dysphagia that lasted 4-7 days, less than that reported with the APC technique; notably, no patients exhibited permanent dysphagia. Dysphagia following instrumentation with APC implies that plate design may have an effect on soft tissue structures; possible explanations include postoperative soft tissue edema, esophageal injury, postoperative hematoma, and adhesive formations around implanted cervical 
plates [19]. Low-profile implants are completely contained in the intervertebral space, avoiding mechanical stimulus to the esophagus; furthermore, the operative procedure is simpler, with reduced retraction of the esophagus, diminishing the risk of postoperative dysphagia [20]. Patients undergoing three-level fusion have significantly higher incidence of postoperative dysphagia than those undergoing one- or two-level fusions, because of the iatrogenic irritation to soft tissues during surgical exposure [21]; therefore, we recommend gentle dissection of cervical tissues and adequate surgical level planning to reduce the incidence of postoperative complications related to the procedure.

Only stable bony fusion prevents delayed kyphotic deformity with concomitant foraminal stenosis causing root compression and neck pain. When single-level ACDF is performed, $83 \%-100 \%$ of radiographic fusion is reported with both techniques [18]. In multilevel cervical disease, bony fusion rates and postoperative sagittal balance have varied among studies as well as on the basis of parameters used for evaluation; fusion rates for multilevel cervical disc degenerative disease vary from $78 \%-100 \%[7,22]$. Chen et al. [7] reported similar rates of fusion between both techniques (APC versus LSC) in multilevel cervical disease (95.7\% versus $92.3 \%$ ). We observed total fusion in $84.9 \%$ of patients (Fig. 2A), with significantly higher rates of fusion in the single level procedure than in multilevel surgery (95.8\% versus $75.9 \%$ ); however, there was no significant difference in clinical outcome between both groups. Long-term results must be evaluated, and other factors beyond technique should be considered during evaluation; these include bone quality of the patients, implant used, distraction achieved by cage usage, and grade of subchondral bone exposure during the meticulous preparation of the endplate for fusion.

During the process of bone remodeling, the settlement of the cage of $<2 \mathrm{~mm}$ into the vertebral bodies until fusion is to be expected; subsidence is defined as the sinking of an object with a greater elasticity modulus (cage) into an object with a lower elasticity modulus (vertebral body) [1]. If the cage subsides into the vertebral body with disc space collapse, foraminal height and cervical alignment are not restored $[8,14]$. Subsidence has been reported in 9.3 to $62.5 \%$ of cervical segments analyzed, and it often occurs within 3 months after surgery [8,14,22-24]. Although subsidence does not appear to affect clinical outcomes, this must be evaluated in long-term studies [7,25-27]. We observed cage subsidence in $11.3 \%$ of our patients, that was within the range reported in previous series. In a onelevel procedure, no significant difference was present between the two techniques, and subsidence risk increased with the number of levels treated; it was more common in C5-6 and C6-7 levels, as we observed in the present study $[1,4]$. With a greater increase in interbody height, the risk for subsidence also increases, suggesting that oversized cages may be a risk factor for subsidence [1]; we found no difference in the incidence of subsidence between single and multilevel procedures. Nevertheless, the long-term clinical outcome of patients with subsidence remains satisfactory, as the disc height of treated level at final followup remains significantly greater that that before surgery; moreover, after fusion, subsidence does not progress $[1,18,28]$. Kao et al. [1] reported no subsidence-related symptoms that required treatment during follow-up in a series of patients treated with LSC for cervical disc disease. In our series, we found no difference in clinical outcome evaluated by NDI and VAS between subsidence and no-subsidence groups. There are no objective parameters for use in determining the correct size cage or predicting clinical outcome $[1,29]$.

Sagittal misalignment will cause an increased stress distribution on internal fixation devices, as well as cervical instability, postoperative axial pain, and deterioration of neurological deficit; these parameters influence functional recovery [18]. In addition, maintenance of cervical alignment is important because malalignment leads to adjacent segmental degeneration of the fused segment and can also cause worsening of long-term outcomes [22]. We observed improvement in cervical lordosis of $5.7^{\circ}$ without significant difference between single and multilevel disease. Both APC and LSC improved local and global sagittal balance in single and multilevel cervical degenerative disease; some studies have shown no significant differences in cervical angles between these techniques $[4,15]$.

Incidence of adjacent segment disease following ACDF has been reported in approximately $25 \%$ of patients [30]. Peri-plate ossification has been previously described as a finding following arthrodesis with anterior cervical plate; notably, there is a higher incidence of adjacent segment degeneration if an additional plate is placed close to an adjacent disc space [15]. With LSC, the incidence of adjacent segment disease is reported from $2 \%$ to $30 \% \%$ at follow-up [18]. We found adjacent segment changes in sequential postoperative studies in nine patients (17\%), 
with no difference between single and multilevel disease; moreover, there was no difference in clinical outcome (Fig. 2B). These findings suggest that even with the LSC technique, there is a significant risk of adjacent segment disease, and additional follow-up is needed to evaluate clinical outcome related to adjacent segment changes in imaging studies.

Case-control studies involving patients surgically treated with ACDF via LSC versus APC technique are needed; furthermore, long-term consequences of complications (e.g., subsidence, sagittal misalignment, adjacent segment disease, and pseudoarthrosis) must be addressed for further analysis of clinical and radiological results.

\section{Conclusions}

Stand-alone ACDF with zero-profile stand-alone cervical devices is an excellent option for cervical degenerative disc disease of one, two, and three levels; similar results were reported with ACDF using either a cage or a plate.

\section{Conflict of Interest}

No potential conflict of interest relevant to this article was reported.

\section{References}

1. Kao TH, Wu CH, Chou YC, Chen HT, Chen WH, Tsou HK. Risk factors for subsidence in anterior cervical fusion with stand-alone polyetheretherketone (PEEK) cages: a review of 82 cases and 182 levels. Arch Orthop Trauma Surg 2014;134:1343-51.

2. Han SY, Kim HW, Lee CY, Kim HR, Park DH. Standalone cages for anterior cervical fusion: are there no problems? Korean J Spine 2016;13:13-9.

3. Smith GW, Robinson RA. The treatment of certain cervical-spine disorders by anterior removal of the intervertebral disc and interbody fusion. J Bone Joint Surg Am 1958;40:607-24.

4. Nambiar M, Phan K, Cunningham JE, Yang Y, Turner PL, Mobbs R. Locking stand-alone cages versus anterior plate constructs in single-level fusion for degenerative cervical disease: a systematic review and meta-analysis. Eur Spine J 2017;26:2258-66.

5. Pfirrmann CW, Metzdorf A, Zanetti M, Hodler J, Boos N. Magnetic resonance classification of lumbar inter- vertebral disc degeneration. Spine 2001;26:1873-8.

6. Scheer JK, Tang JA, Smith JS, et al. Cervical spine alignment, sagittal deformity, and clinical implications: a review. J Neurosurg Spine 2013;19:141-59.

7. Chen Y, Lu G, Wang B, Li L, Kuang L. A comparison of anterior cervical discectomy and fusion (ACDF) using self-locking stand-alone polyetheretherketone (PEEK) cage with ACDF using cage and plate in the treatment of three-level cervical degenerative spondylopathy: a retrospective study with 2-year followup. Eur Spine J 2016;25:2255-62.

8. Gercek E, Arlet V, Delisle J, Marchesi D. Subsidence of stand-alone cervical cages in anterior interbody fusion: warning. Eur Spine J 2003;12:513-6.

9. Healy AT, Sundar SJ, Cardenas RJ, et al. Zero-profile hybrid fusion construct versus 2-level plate fixation to treat adjacent-level disease in the cervical spine. J Neurosurg Spine 2014;21:753-60.

10. Yan B, Nie L. Clinical comparison of zero-profile interbody fusion device and anterior cervical plate interbody fusion in treating cervical spondylosis. Int J Clin Exp Med 2015;8:13854-8.

11. Dong J, Lu M, Lu T, et al. Meta-analysis comparing zero-profile spacer and anterior plate in anterior cervical fusion. PLoS One 2015;10:e0130223.

12. Nemoto O, Kitada A, Naitou S, Tachibana A, Ito Y, Fujikawa A. Stand-alone anchored cage versus cage with plating for single-level anterior cervical discectomy and fusion: a prospective, randomized, controlled study with a 2-year follow-up. Eur J Orthop Surg Traumatol 2015;25:S127-34.

13. Tabaraee E, Ahn J, Bohl DD, et al. Comparison of surgical outcomes, narcotics utilization, and costs after an anterior cervical discectomy and fusion: standalone cage versus anterior plating. Clin Spine Surg 2017;30:E1201-5.

14. Cao L, Chen Q, Jiang LB, et al. Bioabsorbable selfretaining PLA/nano-sized $\beta$-TCP cervical spine interbody fusion cage in goat models: an in vivo study. Int J Nanomedicine 2017;12:7197-205.

15. Park JB, Cho YS, Riew KD. Development of adjacentlevel ossification in patients with an anterior cervical plate. J Bone Joint Surg Am 2005;87:558-63.

16. Fengbin Y, Xinwei W, Haisong Y, Yu C, Xiaowei L, Deyu C. Dysphagia after anterior cervical discectomy and fusion: a prospective study comparing two anterior surgical approaches. Eur Spine J 2013;22:1147- 
51.

17. Olsson EC, Jobson M, Lim MR. Risk factors for persistent dysphagia after anterior cervical spine surgery. Orthopedics 2015;38:e319-23.

18. Li Z, Wang H, Li L, Tang J, Ren D, Hou S. A new zero-profile, stand-alone Fidji cervical cage for the treatment of the single and multilevel cervical degenerative disc disease. J Clin Neurosci 2017;41:115-22.

19. Lee MJ, Bazaz R, Furey CG, Yoo J. Influence of anterior cervical plate design on dysphagia: a 2-year prospective longitudinal follow-up study. J Spinal Disord Tech 2005;18:406-9.

20. Son DK, Son DW, Kim HS, Sung SK, Lee SW, Song GS. Comparative study of clinical and radiological outcomes of a zero-profile device concerning reduced postoperative dysphagia after single level anterior cervical discectomy and fusion. J Korean Neurosurg Soc 2014;56:103-7.

21. Fountas KN, Kapsalaki EZ, Nikolakakos LG, et al. Anterior cervical discectomy and fusion associated complications. Spine 2007;32:2310-7.

22. Choi MK, Kim SB, Park CK, Kim SM. Comparison of the clinical and radiologic outcomes obtained with single- versus two-level anterior cervical decompression and fusion using stand-alone PEEK cages filled with allograft. Acta Neurochir 2016;158:481-7.

23. Schmieder K, Wolzik-Grossmann M, Pechlivanis I, Engelhardt M, Scholz M, Harders A. Subsidence of the wing titanium cage after anterior cervical interbody fusion: 2-year follow-up study. J Neurosurg Spine 2006;4:447-53.

24. Oh JK, Kim TY, Lee HS, et al. Stand-alone cervical cages versus anterior cervical plate in 2-level cervical anterior interbody fusion patients: clinical outcomes and radiologic changes. J Spinal Disord Tech 2013;26:415-20.

25. Zajonz D, Franke AC, von der Hoh N, et al. Is the radiographic subsidence of stand-alone cages associated with adverse clinical outcomes after cervical spine fusion?: an observational cohort study with 2-year follow-up outcome scoring. Patient Saf Surg 2014;8:43.

26. Wang Z, Jiang W, Li X, et al. The application of zeroprofile anchored spacer in anterior cervical discectomy and fusion. Eur Spine J 2015;24:148-54.

27. Zhou J, Li X, Dong J, et al. Three-level anterior cervical discectomy and fusion with self-locking standalone polyetheretherketone cages. J Clin Neurosci 2011;18:1505-9.

28. Wu WJ, Jiang LS, Liang Y, Dai LY. Cage subsidence does not, but cervical lordosis improvement does affect the long-term results of anterior cervical fusion with stand-alone cage for degenerative cervical disc disease: a retrospective study. Eur Spine J 2012;21:1374-82.

29. Yang JJ, Yu CH, Chang BS, Yeom JS, Lee JH, Lee CK. Subsidence and nonunion after anterior cervical interbody fusion using a stand-alone polyetheretherketone (PEEK) cage. Clin Orthop Surg 2011;3:16-23.

30. Ji GY, Oh CH, Shin DA, et al. Stand-alone cervical cages versus anterior cervical plates in 2-level cervical anterior interbody fusion patients: analysis of adjacent segment degeneration. J Spinal Disord Tech 2015;28:E433-8. 